\title{
Zu guter Letzt
}

Wirklich alle (individual-)arbeitsrechtlichen Problemfelder anzureißen - das ist in einem Werk dieses Formats leider kaum möglich. Ich gebe zu, einzelne Themenfelder habe ich Ihnen unterschlagen.

So habe ich Dinge wie Details zum Arbeitsschutz, das allgemein beliebte und bekannte bEm (betriebliches Eingliederungsmanagement), die Arbeitnehmerhaftung für Schäden und fast das ganze Kollektivarbeitsrecht (Stichwort: Betriebsrat) etc. außen vor gelassen.

Dies hat im Wesentlichen zwei Gründe:

Zum einen will ich Sie nicht mit juristischer Detailversessenheit erschlagen.

Zum anderen plane ich bereits jetzt eine Fortsetzung dieses Werks und wer weiß, vielleicht gibt es auch noch eines Tages Teil 3. Immerhin hat „Rocky“ es ja auch auf inzwischen 7 Teile gebracht.

Ich hoffe, dass Ihnen dieses Büchlein dennoch auf Ihrem Weg durch das deutsche Arbeitsrecht ein brauchbarer Begleiter ist und Ihnen die nötigen Denkanstöße liefert. Für alles Weitere bin ich ja da.

Herzlichst

$\mathrm{Ihr}$

Urs Peter Janetz

Fachanwalt Für Arbeitsrecht 